\title{
Learning Strategies of the Arab EFL Learners: Finding Correlation with Outcomes
}

\author{
Arif Ahmed Mohammed Hassan Al-Ahdal (Corresponding author) \\ College of Science and Arts, Methnab, Qassim University, Saudi Arabia \\ E-mail: arif_al_ahdal@yahoo.com \\ Ahmed Ali Hassan Al-Ma'amari \\ College of Education, Qassim University, Saudi Arabia \\ E-mail:mamarih@yahoo.com
}

Doi:10.7575/aiac.alls.v.6n.5p.230

Received: 02/06/2015

URL: http://dx.doi.org/10.7575/aiac.alls.v.6n.5p.230

Accepted: 13/08/2015

\begin{abstract}
Socio-psychological research and findings into learner differences led to the emergence of learner strategies research in the last century. With major contributions from the emerging field of Linguistics in the mid 1970s, language learning strategies began to receive considerable attention. It is worth noting that the primary concern of most of the studies on language learning strategies has been the identification of the characteristic of good language learners and what it is that they do to learn a second language ! The focus of this study, consequently, is the teaching of language learning strategies to facilitate better learning. It aims at differentiating the strategies of good language learners from those of poor language learners. The hypothesis is this would enable language teachers to propagate the successful strategies to ensure better learning outcomes: A major factor for socio-economic development in KSA. It analyses the strategies used by Saudi students in learning English as a foreign language. Further, it brings out the teacher's role in raising the students' awareness of different strategies, educating the teachers in the use of these strategies, and training them to assimilate these into regular classroom activities. Instruments used include a questionnaire administered to the students and interviews with the teachers.
\end{abstract}

Keywords: Strategies, EFL, Saudi students, learning outcomes, learner differences

\section{Introduction}

Psycholinguistic studies into foreign language acquisition in recent years have positively correlated many variables with successful learning outcomes. These studies classify learners into different categories depending upon the learning style most successful with them. For instance, a kinaesthetic learner will learn the best when learning for him/her is integrated with activities involving movement. On the other hand, the lecture method is most successful with the auditory learner. Further, the analytic learner is likely to look for minute details in a learning experience whereas the global learner may prefer learning through global exposure. Thus, the learning environment is believed to influence the learner's response to methods of presenting language. These characteristics are now seen as aspects of learning style or cognitive style. Apart from these, culture as learned by the learner from family, school and community is also known to influence the learning style. In the current study, however, the subjects being mono cultural (Arab), we have discounted this factor and focused on documenting the learning strategies of the EFL learners, correlating these with the learning outcomes (the performance in tests later administered), and finally, highlighting the specific strategies of the 'good learners'. The idea that the strategies of the 'good learners' are identifiable and implementable in the classroom is an area of interest for us as we have attempted here to find ways of improving the learners' strategies (on the assumption that every learner applies one or the other strategy for language acquisition) and raising their awareness about other strategies that they might develop. The large scale implication of the study is for teachers and textbook writers whose contribution to the field of EFL can be made more meaningful in the light of the findings of this paper.

\section{Literature Review}

In a study in 1982, Diekhoff et al. described a learning strategy training programme based on network models of long term memory structure and depth-of-processing theory. The study came up with evidence which supported the effectiveness of learning strategy training program in enhancing prose learning.

Findings of Oxford and Oxford et al in different studies (1989, 1990, 1992, 1993) brought out a variety of results: i) Gender and ethnicity (two learner characteristics) are determinants of strategy use; ii) Learning strategies cannot be torn apart as learning outcomes are a result of combined use of many of these; iii) Language learning strategies enable students to gain a large measure of responsibility for their own progress, and there is considerable evidence that effective strategy can be taught; iv) Learner training which often involves teaching better strategy use and sometimes addresses individual learning styles as well, has been highly successful in some instances and not in others; v) The best 
learner training includes an explicit and clear focus on specific strategies, has frequent practice opportunities for strategies, is integrated with regular classwork, and shows students how to transfer strategies to new situations.

Guskey (1990) in Cooperative Mastery Learning Strategies talked of four common premises shared by these two strategies viz., (1) criterion referenced assessment of student learning, (2) emphasis on the teacher's role as an instructional leader and learning facilitator, (3) flexibility in application, (4) strong theoretical and research foundations. These findings are relevant to the current study as well.

Maclntyre and Gardner (1991) observed that the use of certain affective (emotion or motivation related) learning strategies reduces the level of language anxiety, thus freeing up cognitive resources to be applied to the use of cognitive learning strategies.

In a study in 1994, Mclntyre highlights that a complex combination of affective factors are at play in language learning situations: task demands, proficiency, aptitude, situation, attitude, motivation, previous success, anxiety, self confidence, sanctions against strategy use, goals, and criteria for success. This model allows for strategy use to be context dependent.

Karabenick and Eaglin (1997) found out what the current study would like to highlight especially in the context of the Saudi EFL classroom with grades at the centre: The students in classes with greater emphasis on collaboration and less emphasis on grades were more likely to use higher order learning strategies of elaboration and critical thinking.

Isabella Kojic Sobo and Patsy M. Lightbown in Students' Approaches to Vocabulary Learning and their Relationship to Success (1999) assert that Learner initiative and independence, along with the amount of extracurricular time spent on language (and vocabulary) learning, are seen as two crucial factors related to higher levels of achievement.

Bruen (2001) studied the parallel development of oral proficiency and use of language learning proficiency and found that the more effective language learners use progressively more language learning strategies overtime, in particular, more cognitive, metacognitive, and social strategies. This resonates in part the findings of this study.

All of our data suggest that, learner individuality notwithstanding, some elements in the acquisition process are equally crucial in both second and foreign language learning environ-ments. The importance of time is probably less interesting in itself, because it has always been emphasized in SLA situations that mastering another language takes time. Furthermore, time alone does not seem to suffice. Foreign language learning also takes initiative on the learner's part, a willingness to put extra effort into the learning process, to take it outside the classroom, and to build on it by independent learning activities. The target language environment provides a head start for ESL students in these endeavours, but EFL learners can overcome this inherent disadvantage by engaging in a variety of language learning activities on their own and by doing their studies elaborately enough to ensure depth of processing and greater success.

In 10 Best Teaching Practices (2011), Donna Walker Tileston categorizes learners on the basis of three main learning styles: Auditory; Visual; and Kinesthetic. She suggests that teachers can try one or more of the following for teaching the auditory learners: i) Direct instruction, in which the teacher guides the learning through the application of declarative and procedural ii) Employ peer tutoring, in which students help each other practice the learning iii) Plan activities that incorporate music iv) Teach using group discussion, brainstorming, and Socratic seminars v) Assign specific oral activities vi) Verbalize while learning vii) Use cooperative learning activities. For the visual learners she advises inclusion of the following: i) Use visuals when teaching ii) Directly teach students to use visual organizers and provide enough practice so that the process is automatic to the student iii) Show students the patterns in the learning. Similarly for the kinaesthetic learner providing opportunities for movement in the classroom can make a tremendous difference. Additionally, the following may be employed: i) Use a hands-on approach ii) Provide opportunities to move iii) Use simulations when appropriate iv) Bring in music, art, and manipulatives v) Break up the lecture so that it is in manageable chunks vi) Use discovery learning when appropriate vii) Use such techniques as discussion or cooperative learning so that these students have an opportunity to move about and talk to their peers.

\subsection{Strategies of the 'Good' language learner}

According to Rubin (1975) and Naiman et al (1978) as quoted in Methods of Teaching English (CIEFL, 1995) there are certain identifiable characteristics of good language learners which are relevant to formal as well as informal language learning opportunities. They i) have a positive approach to language learning; ii) look for opportunities for language use in meaningful situations; iii) use study techniques like making vocabulary lists; iv) monitor their own errors; v) are not inhibited in using the language or of making mistakes; vi) are willing to take risks when using the language; vii) adapt to different learning conditions.

According to Naiman, Frohlich, and Todesco (1975); Naiman, Frohlich, Stern and Todesco (1978); Rubin (1975); Stern (1983), characteristics of good language learners will include a variety of learning strategies, such as taking advantage of practice opportunities, willingly and accurately guessing, handling emotional issues in language learning, consciously developing the L2 as a meaning system and a structure system and monitoring one's own speech.

In their Think Aloud Studies Abraham and Vann (1987); O’Mallet and Chamot (1990) found that effective L2 learners are aware of the strategies they use and why they use them. Such learners manage to adapt their strategies to the language task and to their personal needs as learners. However they do not know how to choose the appropriate strategies or how to link them together into a useful 'strategy chain'. 
O'Malley et al. (1985) report on a study that identified appropriate learning strategies for students and demonstrated that explicit instruction in the use of the strategies significantly improved student performance. The authors concluded that the teaching of learning strategies, coupled with the application of those strategies in a subject-area discipline, greatly enhanced student learning.

Strategy-based instruction refers to classroom procedures where the teacher incorporates language learning strategies in language teaching (Cohen 1998; Chamot et al. 1999). It is proposed because a rich body of literature shows that higherproficiency students are more likely to use learning strategies than their lower-proficiency counterparts and that the former tend to use them more flexibly and effectively in relation to the context that requires the use of such learning strategies for maximal learning outcomes (Cohen 1998; Harris 2003; McDonough 1999; O'Malley and Chamot 1990; Oxford 2001; Zhang 2003).

In Teaching and Learning in the Language Classroom (2010), Tricia Hedge sums up what the theorists tell us are the characteristics of a good (English) learner. He/she is i) confident in his/her ability to learn ii) self reliant iii) motivated and enthusiastic iv) aware of why he/she wants to learn v) unafraid of making mistakes vi) unafraid of what he/she doesn't know vii) a good risk taker viii) a good guesser ix) probably positive in his/her attitude to English language and culture $\mathrm{x}$ ) a good pattern receiver xi) prepared to look for opportunities to come into contact with the language xii) willing to assume a certain responsibility for his/her own learning.

\subsection{Classifying Learning Strategies}

Starting with the early studies in language research to the current times, identification and classification of strategies have undergone much change. These however, converge at a point: being based on learner response, they investigate only conscious strategies; the 'automatic' or unconscious processes still need to be studied.

In a study similar to this in EFL context in Taiwan, Ying Chun Lai (2009), presented a strategy classification table adapted from Oxford (1990). This categorizes learning strategies into two types, viz. Direct and Indirect. The sub categories are as follows:

\subsubsection{Direct Strategies}

1. Memory Strategies: Help learners store and retrieve new information (e.g. applying images and sounds, creating mental linkages)

2. Cognitive strategies: Applied by learners to better understand and produce the target language (e.g. summarizing, analyzing, reasoning)

3. Compensatory Strategies: Used for overcoming deficiencies in knowledge in the target language (e.g. guessing meaning from a context, using synonyms to convey meaning)

\subsubsection{Indirect Strategies}

1. Metacognitive Strategies: Allow leaners to control their own cognition (e.g. coordinating the planning, organizing, and evaluation of the learning process)

2. Affective Strategies: Refer to the methods that help learners to regulate emotions, motivation, and attitudes (e.g. self encouragement)

3. Social Strategies: Include interaction with others through the target language (e.g. asking questions, cooperating with native speakers, becoming culturally aware)

Oxford's taxonomy summarises largely the variety of efforts at strategy classification. Therefore, it is this classification that has been employed in the current study.

\subsection{Research Questions}

This study was initiated with the following questions:

1. What are the trends and patterns, if any, of language learning strategy use by EFL learners in Saudi Arabia?

2. Is there a difference in strategies employed by the proficient learners and the less proficient ones?

3. Is there a positive correlation between the strategies of the 'good learners' and their level of proficiency?

4. Which, if any or more, learning strategy/ies is/are the most widely applied by EFL learners in Saudi Arabia?

\section{Methodology}

A questionnaire comprising fifty questions was prepared for the purpose of this study. This is based on the Strategy Inventory for Language Learning (SILL) Version 7.0 developed by Oxford (1990). This is a self reporting questionnaire on language learning strategy. It is a Likert scaled five point tool where 1 stands for 'never or almost never' and 5 stands for 'always or almost always' We used this tool for its simplicity (of comprehension) with respect to the subjects and also because it takes a very short time to answer: The questionnaire was administered by the language teachers to the secondary level students (160 in all) spread over ten schools in Qassim, Saudi Arabia. Prior to the experiment, the mean average for English scores of each subject was calculated based upon their performance in the last two school terms and a proficiency test especially administered by us. This tested them on comprehension, grammar, writing, and speaking/listening.

The strategy wise classification of the questionnaire items was based on Lai (2009) as follows: items 1-9 are memory based; 10-23 are cognition based; 24-29 are on compensation strategies; 30-38 are based on meta-cognitive strategies; 39-44 are affective strategies based; $45-50$ are based on social strategies. 
Reliability: According to Oxford (1990), reliability for the SILL is high across many cultural groups with Cronbach's alpha for internal consistency 0.93-0.98 (Oxford and Burry Stock, 1995). In the study, this value was 0.94.

Once the data was collected, we calculated the mean score for each strategy. We also calculated the mean score of the entire SILL for each subject. However to make the data more usable, we used a cut off range of 13-20 to classify learners as 'good learners' and a range of 3-12 to isolate the 'poor learners'. Responses of strategy use below four, ie, where the subject reported using three or lesser number of strategies were discarded.

\section{Outcomes and Implications}

The representation indicates high correlation between the subjects' proficiency and SILL response. For the higher proficiency mean scores, the SILL reading is also high. This can imply one or both of these: (1) The more proficient users apply a larger number of strategies, and/or (2) They apply adeptly one or more of the strategies. In either case the correlation between learning output and strategy use appears well established.

Here are the Correlation Coefficients of each of the five learning strategies with the total SILL scores: As language learning strategies, cognition and metacognition show a predictably high correlation at 0.894 and 0.906 respectively. The correlation with memory, compensation, and affective strategies also exists but is much less at $0.214,0.207$, and 0.401 respectively. In the given EFL situation, it is ironical that these very strategies, if any worth the mention, are applied in the classrooms. No wonder then that learning outcomes are not as desired.

The correlation of scores obtained by the subjects in Term 1, Term 2 and the 'Proficiency Test' designed by the researchers with the total marks is almost perfect, viz. $0.978141,0.959561$ and 0.967799 respectively. The implications are as follows:

1. The efficiency of the three tests is established beyond doubt- all the three are not random but rather there are very strong, positive correlations with the overall result.

2. Likewise, when the marks of Term 1, and Term 2 were individually correlated with the test designed by us, high positive correlations were discovered.

3. The correlations between the two Term results was even higher, indicating consistency in the testing materials and the methods of internal testing. But the correlation between Term 1 and the test also showed a high correlation which was only slightly less than (2) above. This shows that the testing materials and procedures were comparable to those of the external test administered by us. This, of course, presumes that the student population is a constant.

When the components of SILL were correlated with total proficiency (which constituted of Term 1, Term 2 and the test designed by us, which we choose to call 'Our Test'), then very interesting results were obtained. They are presented below:

1. The following strategies, namely, Memory, Cognition, Metacognition and Affective have positive correlation with the total result of the Proficiency Test, whereas, compensation is negatively correlated.

2. From the above, we deduced that the strategy of Compensation is not only not helpful in enhancing the learners' performance, it in fact, hinders it.

3. Students with low proficiency are forced to use this strategy and hence, the use of Compensation as a strategy is a symptom rather than the cause of poor proficiency. This theory can be a matter of further research.

4. Memory and total proficiency are very weakly correlated, as the coefficient for this stands at a poor 0.069626507 , i.e., less than 1 .

5. Likewise, Affective strategies yield a mild correlation at 0.189927888 with the total performance.

6. Cognition and Metacognition show a very robust correlation at 0.898281091 and 0.881081753 respectively with the total Proficiency scores.

\section{Conclusion}

This study has several pedagogical implications. For one it shows that making learners memorise language items as is the scenario of EFL classroom in Saudi Arabia will not lead to successful language learning. Further, Affective strategies, i.e., relating the materials to real life experiences, emotions etc. is also a casualty in the given study. This calls for a thorough revamping of the materials if the learners are to be enabled to use this strategy. It is also clear that the proficient learners use a variety or combination of strategies. The most successful learning strategies are Cognitive and Meta-cognitive. This implies that it is important to make the learners aware of their learning process and teaching to them the possibility of using these. If we are to develop autonomous, self motivated, efficient learners, it is imperative to train them in the use of these strategies and helping them discover and develop their unique ways of learning. This finding agrees with those of Wharton (2000), Bruen (2001) and Peacock (2003) among many others: Cognitive and meta-cognitive strategies correlate positively to better language proficiency. Foreign language learners (of English in this case) can be helped to channelize their cognition to better understand and produce language: this should also be the focus of EFL instruction. The EFL teachers in Saudi Arabia should assist the poor learners in planning their learning: Analysing and practicing English sounds and looking for language use opportunities even outside the classroom. Also within the classroom, teachers should encourage learners to explore and employ the strategies they ignore but which the study has proven effective: the strategies of the 'good learners'. Classroom environment should be enriched with emphasis on learning, using and practicing English to the exclusion of Arabic. This suggestion needs special attention since like most EFL classrooms, the teachers and learners in Saudi EFL classrooms soon resort to the mother tongue. 
Finally, one unique language learning strategy can be encouraging the proficient learners to share their strategies on a one to one basis with the less proficient ones.

\section{References}

Brown, T. S., Perry, Jr., Fred, L. (1991). A Comparison of Three Learning Strategies for ESL Vocabulary Acquisition. TESOL Quarterly, 25(4),655-670.

Bruen, J. (2001). The Parallel Development of Oral Proficiency and Use of Language Learning Strategies. Die Unterrichtspraxis/ Teaching German, 34(2),158-168.

Carrell, P.L., Pharis, B.G., Liberto, J. C. (1989). Metacognitive Strategy Training for ESL Reading. TESOL Quarterly, 23(4), 647-678.

Chamot, A.U., \& Dinary, P.B. (1999). Children's Learning Strategies in Language Immersion Classrooms. The Modern Language Journal, 83(3), 319-338.

Diekhoff, G. M., Brown, P. J., \& Danserau, D. F. (1982). A Prose Learning Strategy Training Program Based on Network and Depth-of-Processing Models. The Journal of Experimental Education, 50(4), 180-184.

Ferris, D. \& Tagg, T. (1996). Academic Listening/Speaking Tasks for ESL Students: Problems, Suggestions, and Implications. TESOL Quarterly, 30(2), 297-320.

Gonzalez, O., \& Gonzales, O. (1999). Building Vocabulary: Dictionary Consultation and the ESL Student. Journal of Adolescent \& Adult Literacy, 43(3), 264-270.

Green, J. M., \& Oxford, R. (1995). A Closer Look at Learning Strategies, L2 Proficiency, and Gender. TESOL Quarterly, 29(2), 261-297.

Guskey, T. R. (1990). Cooperative Mastery Learning Strategies. The Elementary School Journal, 19(1), 33-42.

Hedge, T. (2010). Teaching and Learning in the Language Classroom. Oxford University Press, Oxford.

Hsiao, T.Y. , \& Oxford, R. (2002). Comparing Theories of Language Learning Strategies: A Confirmatory Factor Analysis. The Modern Language Journal, 86(3), 368-383.

Jang, E.Y. , \& Jiménez, R. T. (2011). A Sociocultural Perspective on Second Language Learner Strategies: Focus on the Impact of Social Context. Theory into Practice, 50(2), 141-148.

Johnson, D., \& Steele, V. (1996). So Many Words, so Little Time: Helping College ESL Learners Acquire VocabularyBuilding Strategies. Journal of Adolescent \& Adult Literacy, 39(5), 348-357.

Karabenick, S. A., \& Eaglin, J.C. (1997). Relation of Perceived Instructional Goals and Incentives to College Students' Use of Learning Strategies. The Journal of Experimental Education, 65(4), 331-341.

Leki, I. (1995). Coping Strategies of ESL Students in Writing Tasks across the Curriculum. TESOL Quarterly, 29(2), 235-260.

Locastro, V. (1994). Learning Strategies and Learning Environments. TESOL Quarterly, 28(2), 409-414.

Macaro, E. (2006). Strategies for Language Learning and for Language Use: Revising the Theoretical Framework. The Modern Language Journal, 90(3), 320-337.

McDonough, Sh. K. (2001). Promoting Self-Regulation in Foreign Language Learners. The Clearing House, 74(6), 323-326.

Miller, J.R. (1993). A Critical Appraisal of Learner Training: Theoretical Bases and Teaching Implications. TESOL Quarterly, 27(4), 679-689.

Mokhtari, K. \& Sheorey, R. (2002). Measuring ESL Students' Awareness of Reading Strategies. Journal of Developmental Education, 25(3), 2-10.

Moussu, L. (2010). Influence of Teacher-Contact Time and Other Variables on ESL Students' Attitudes Towards Native- and Nonnative-English-Speaking Teachers. TESOL Quarterly, 44(4), 746-768.

O'Malley,J. \& Michael et al. (1985). Learning Strategy Applications with Students of English as a Second Language. TESOL Quarterly, 19(3), 557-584

Oxford, R., \& Crookall, D. (1989). Research on Language Learning Strategies: Methods, Findings, and Instructional Issues. The Modern Language Journal, 73(4), 404-419

Pappamihiel, N. E . (2002). English as a Second Language Students and English Language Anxiety: Issues in the Mainstream Classroom. Research in the Teaching of English, 36(3). 27-355

Recker, M., \& Pirolli, P . (1995). Modeling Individual Differences in Students' Learning Strategies. The Journal of the Learning Sciences, 4(1),1-38.

Reid, J. M. (1987). The Learning Style Preferences of ESL Students. TESOL Quarterly, 21(1).87-111

Sabo, I.K., \& Lightbown, P. M. (1999). Students' Approaches to Vocabulary Learning and Their Relationship to Success. The Modern Language Journal, 83(2), 176-192

Tileston, D.W. (2014). 10 Best Teaching Practices. Sage Advatedge, India 
Statistical Representations of Readings

Correlations of the Tests with the Total Marks

$0.98 \longrightarrow 0.978140559$

0.975

0.97
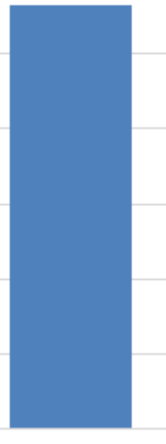

Term 1 (MM 40)

0.96779894

0.959560946


Test (MM 50)

\section{Correlations Between the Tests}

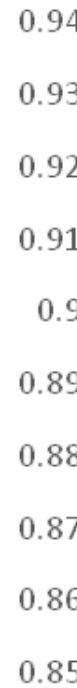

0.926941955

0.93

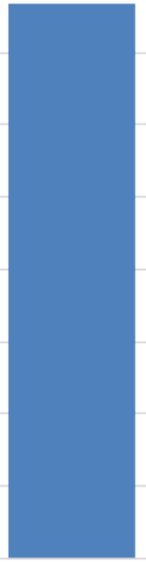

0.916521716

Term 1 Vs. Term 2

Term 1 vs. Test

Term 2 Vs. Test

\section{Correlations with Proficiency (Total)}

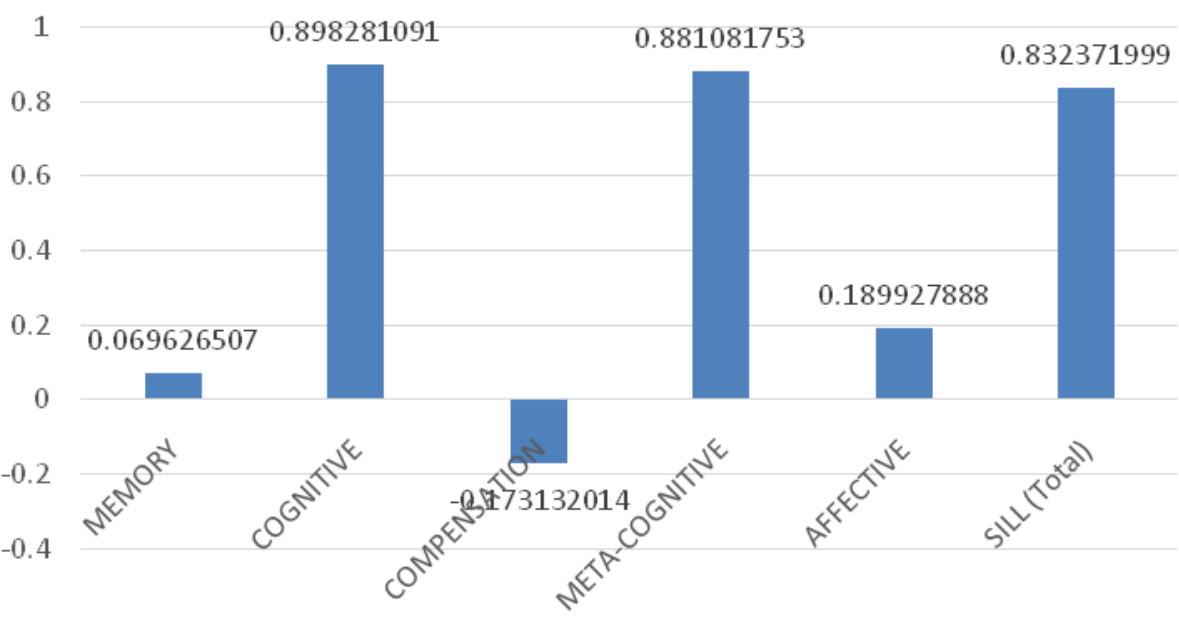




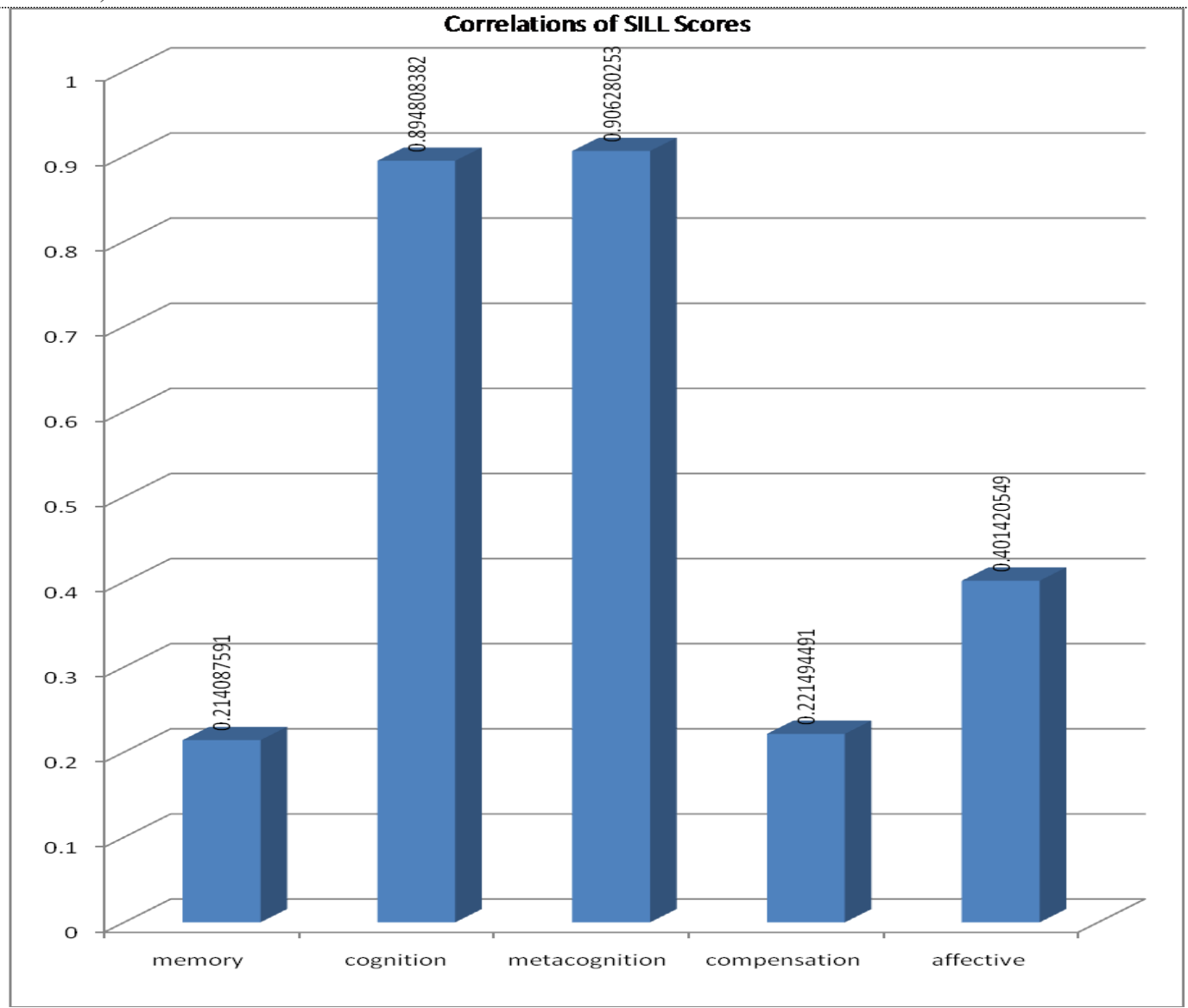

Table 1. SILL Scores

(On a scale of 1-5, where 1 means never or almost never and 5 means always or almost always)

\begin{tabular}{|c|c|c|c|c|c|c|}
\hline 1. & - & 1 & 3 & 1 & 2 & 7 \\
\hline \multicolumn{7}{|l|}{2.} \\
\hline \multicolumn{7}{|l|}{3.} \\
\hline 4. & 1 & - & 2 & 1 & 1 & 5 \\
\hline \multicolumn{7}{|l|}{5.} \\
\hline 6. & - & - & 3 & 2 & 3 & 8 \\
\hline 7. & 3 & 5 & 2 & 5 & 2 & 17 \\
\hline \multicolumn{7}{|l|}{8.} \\
\hline \multicolumn{7}{|l|}{9.} \\
\hline \multicolumn{7}{|l|}{10.} \\
\hline \multicolumn{7}{|l|}{11.} \\
\hline 12. & 2 & 1 & 1 & - & 2 & 6 \\
\hline \multicolumn{7}{|l|}{13.} \\
\hline \multicolumn{7}{|l|}{14.} \\
\hline \multicolumn{7}{|l|}{15.} \\
\hline \multicolumn{7}{|l|}{16.} \\
\hline \multicolumn{7}{|l|}{17.} \\
\hline \multicolumn{7}{|l|}{18.} \\
\hline 19. & 2 & 4 & 1 & 5 & 2 & 14 \\
\hline \multicolumn{7}{|l|}{20.} \\
\hline \multicolumn{7}{|l|}{21.} \\
\hline 22. & 3 & 1 & 2 & - & 1 & 7 \\
\hline \multicolumn{7}{|l|}{23.} \\
\hline \multicolumn{7}{|l|}{24.} \\
\hline 25. & 1 & 5 & 2 & 5 & 2 & 15 \\
\hline \multicolumn{7}{|l|}{26.} \\
\hline \multicolumn{7}{|l|}{27.} \\
\hline \multicolumn{7}{|l|}{28.} \\
\hline \multicolumn{7}{|l|}{29.} \\
\hline \multicolumn{7}{|l|}{30.} \\
\hline \multicolumn{7}{|l|}{31.} \\
\hline 32. & 2 & 4 & 1 & 4 & 2 & 13 \\
\hline 33. & 1 & 5 & 3 & 5 & 3 & 17 \\
\hline
\end{tabular}




\begin{tabular}{|c|c|c|c|c|c|c|}
\hline 34. & & & & & & \\
\hline 35. & & & & & & \\
\hline 36. & 2 & - & 2 & 1 & 2 & 7 \\
\hline 37. & & & & & & \\
\hline 38. & & & & & & \\
\hline 39. & & & & & & \\
\hline 40. & & & & & & \\
\hline 41. & & & & & & \\
\hline 42. & & & & & & \\
\hline 43. & 3 & 5 & 3 & 4 & 1 & 16 \\
\hline 44. & & & & & & \\
\hline 45. & & & & & & \\
\hline 46. & & & & & & \\
\hline 47. & 2 & 1 & 1 & 1 & 2 & 7 \\
\hline 48. & & & & & & \\
\hline 49. & & & & & & \\
\hline 50. & 4 & 4 & 2 & 4 & 2 & 16 \\
\hline 51. & & & & & & \\
\hline 52. & & & & & & \\
\hline 53. & & & & & & \\
\hline 54. & 2 & 5 & 2 & 5 & 2 & 16 \\
\hline 55. & & & & & & \\
\hline 56. & & & & & & \\
\hline 57. & & & & & & \\
\hline 58. & 1 & - & 3 & 1 & 3 & 8 \\
\hline 59. & & & & & & \\
\hline 60. & & & & & & \\
\hline 61. & 4 & 4 & 3 & 5 & 2 & 18 \\
\hline 62. & & & & & & \\
\hline 63. & & & & & & \\
\hline 64. & & & & & & \\
\hline 65. & & & & & & \\
\hline 66. & 2 & - & 1 & 1 & 1 & 5 \\
\hline 67. & & & & & & \\
\hline 68. & & & & & & \\
\hline 69. & & & & & & \\
\hline 70. & & & & & & \\
\hline 71. & 4 & 3 & 3 & 3 & 5 & 18 \\
\hline 72. & & & & & & \\
\hline 73. & 3 & 5 & 2 & 5 & 3 & 18 \\
\hline 74. & & & & & & \\
\hline 75. & & & & & & \\
\hline 76. & & & & & & \\
\hline 77. & & & & & & \\
\hline 78. & & & & & & \\
\hline 79. & & & & & & \\
\hline 80. & 1 & 4 & 3 & 4 & 4 & 16 \\
\hline 81. & & & & & & \\
\hline 82. & 3 & 1 & 4 & 1 & - & 9 \\
\hline 83. & & & & & & \\
\hline 84. & & & & & & \\
\hline 85. & & & & & & \\
\hline 86. & & & & & & \\
\hline 87. & & & & & & \\
\hline 88. & 1 & 5 & 2 & 5 & 1 & 14 \\
\hline 89. & & & & & & \\
\hline 90. & 2 & - & 1 & - & - & 3 \\
\hline 91. & & & & & & \\
\hline 92. & & & & & & \\
\hline 93. & 3 & 1 & 1 & - & 1 & 6 \\
\hline 94. & & & & & & \\
\hline 95. & & & & & & \\
\hline 96. & & & & & & \\
\hline 97. & 3 & 4 & 3 & 4 & 2 & 16 \\
\hline 98. & 2 & 5 & 4 & 5 & 1 & 17 \\
\hline 99. & & & & & & \\
\hline 100. & & & & & & \\
\hline
\end{tabular}




\begin{tabular}{|c|c|c|c|c|c|c|}
\hline 101. & 1 & 1 & 5 & 1 & 1 & 9 \\
\hline \multicolumn{7}{|l|}{102.} \\
\hline \multicolumn{7}{|l|}{103.} \\
\hline \multicolumn{7}{|l|}{104.} \\
\hline 105. & 3 & 3 & 3 & 4 & 2 & 15 \\
\hline 106. & - & - & 2 & - & 1 & 3 \\
\hline \multicolumn{7}{|l|}{107.} \\
\hline \multicolumn{7}{|l|}{108.} \\
\hline \multicolumn{7}{|l|}{109.} \\
\hline \multicolumn{7}{|l|}{110.} \\
\hline 111. & 1 & 5 & 2 & 5 & 1 & 14 \\
\hline \multicolumn{7}{|l|}{112.} \\
\hline \multicolumn{7}{|l|}{113.} \\
\hline 114. & - & 1 & 3 & - & 1 & 5 \\
\hline \multicolumn{7}{|l|}{115.} \\
\hline \multicolumn{7}{|l|}{116.} \\
\hline \multicolumn{7}{|l|}{117.} \\
\hline \multicolumn{7}{|l|}{118.} \\
\hline \multicolumn{7}{|l|}{119.} \\
\hline \multicolumn{7}{|l|}{120.} \\
\hline \multicolumn{7}{|l|}{121.} \\
\hline 122. & 4 & 5 & 5 & 5 & 1 & 20 \\
\hline 123. & & & & & & \\
\hline 124. & & & & & & \\
\hline 125. & 1 & 4 & 1 & 3 & 1 & 10 \\
\hline 126. & & & & & & \\
\hline 127. & & & & & & \\
\hline 128. & 2 & 1 & 2 & 1 & - & 6 \\
\hline 129. & & & & & & \\
\hline 130. & & & & & & \\
\hline 131. & 2 & 4 & 1 & 5 & 1 & 13 \\
\hline 132. & & & & & & \\
\hline 133. & & & & & & \\
\hline 134. & & & & & & \\
\hline 135. & 3 & - & - & - & 1 & 4 \\
\hline 136. & & & & & & \\
\hline 137. & & & & & & \\
\hline 138. & & & & & & \\
\hline 139. & & & & & & \\
\hline 140. & - & 1 & 3 & 1 & 1 & 6 \\
\hline 141. & & & & & & \\
\hline 142. & & & & & & \\
\hline 143. & 3 & 5 & 1 & 5 & 1 & 15 \\
\hline 144. & & & & & & \\
\hline 145. & 2 & - & 2 & - & - & 4 \\
\hline 146. & 2 & 4 & 2 & 4 & 2 & 14 \\
\hline 147. & & & & & & \\
\hline 148. & & & & & & \\
\hline 149. & & & & & & \\
\hline 150. & 4 & 1 & 1 & 1 & - & 7 \\
\hline 151. & - & 1 & 5 & 1 & 1 & 8 \\
\hline 152. & & & & & & \\
\hline 153. & 3 & 5 & 3 & 5 & 3 & 19 \\
\hline 154. & 2 & 5 & 3 & 4 & 2 & 16 \\
\hline 155. & & & & & & \\
\hline 156. & & & & & & \\
\hline 157. & 5 & 1 & 3 & - & - & 9 \\
\hline 158. & & & & & & \\
\hline 159. & - & - & 4 & - & 2 & 6 \\
\hline 160. & 1 & 2 & 2 & 1 & 1 & 7 \\
\hline
\end{tabular}

Table 2. Proficiency Scale

\begin{tabular}{|c|c|c|c|c|}
\hline 1. & 05 & 07 & 10 & 22 \\
\hline 2. & & & & \\
\hline 3. & & & & 12 \\
\hline 4. & 11 & 08 & 31 \\
\hline
\end{tabular}




\begin{tabular}{|c|c|c|c|c|}
\hline 5. & & & & \\
\hline 6. & 15 & 11 & 15 & 41 \\
\hline 7. & 25 & 16 & 33 & 74 \\
\hline 8. & & & & \\
\hline 9. & & & & \\
\hline 10. & & & & \\
\hline 11. & & & & \\
\hline 12. & 12 & 10 & 16 & 38 \\
\hline 13. & & & & \\
\hline 14. & & & & \\
\hline 15. & & & & \\
\hline 16. & & & & \\
\hline 17. & & & & \\
\hline 18. & & & & \\
\hline 19. & 31 & 26 & 28 & 85 \\
\hline 20. & & & & \\
\hline 21. & & & & \\
\hline 22. & 15 & 10 & 17 & 42 \\
\hline 23. & & & & \\
\hline 24. & & & & \\
\hline 25. & 29 & 22 & 27 & 78 \\
\hline 26. & & & & \\
\hline 27. & & & & \\
\hline 28. & & & & \\
\hline 29. & & & & \\
\hline 30. & & & & \\
\hline 31. & & & & \\
\hline 32. & 32 & 23 & 32 & 87 \\
\hline 33. & 24 & 20 & 25 & 69 \\
\hline 34. & & & & \\
\hline 35. & & & & \\
\hline 36. & 13 & 11 & 20 & 44 \\
\hline 37. & & & & \\
\hline 38. & & & & \\
\hline 39. & & & & \\
\hline 40. & & & & \\
\hline 41. & & & & \\
\hline 42. & & & & \\
\hline 43. & 32 & 24 & 41 & 97 \\
\hline 44. & & & & \\
\hline 45. & & & & \\
\hline 46. & & & & \\
\hline 47. & 18 & 14 & 22 & 54 \\
\hline 48. & & & & \\
\hline 49. & 24 & 19 & 30 & 73 \\
\hline 50. & & & & \\
\hline 51. & & & & \\
\hline 52. & & & & \\
\hline 53. & & & & \\
\hline 54. & 29 & 19 & 27 & 75 \\
\hline 55. & & & & \\
\hline 56. & & & & \\
\hline 57. & & & & \\
\hline 58. & 13 & 8 & 18 & 39 \\
\hline 59. & & & & \\
\hline 60. & & & & \\
\hline 61. & 33 & 25 & 42 & 100 \\
\hline 62. & & & & \\
\hline 63. & & & & \\
\hline 64. & & & & \\
\hline 65. & & & & \\
\hline 66. & 14 & 12 & 20 & 46 \\
\hline 67. & & & & \\
\hline 68. & & & & \\
\hline 69. & & & & \\
\hline 70 . & & & & \\
\hline 71. & 19 & 16 & 23 & 58 \\
\hline
\end{tabular}




\begin{tabular}{|c|c|c|c|c|}
\hline 72. & & & & \\
\hline 73. & 30 & 23 & 37 & 90 \\
\hline 74. & & & & \\
\hline 75. & & & & \\
\hline 76. & & & & \\
\hline 77. & & & & \\
\hline 78. & & & & \\
\hline 79. & & & & \\
\hline 80. & 30 & 21 & 27 & 78 \\
\hline 81. & & & & \\
\hline 82. & 9 & 4 & 12 & 25 \\
\hline 83. & & & & \\
\hline 84. & & & & \\
\hline 85. & & & & \\
\hline 86. & & & & \\
\hline 87. & & & & \\
\hline 88. & 29 & 17 & 38 & 84 \\
\hline 89. & & & & \\
\hline 90. & 10 & 9 & 17 & 36 \\
\hline 91. & & & & \\
\hline 92. & & & & \\
\hline 93. & 15 & 6 & 16 & 37 \\
\hline 94. & & & & \\
\hline 95. & & & & \\
\hline 96. & & & & \\
\hline 97. & 26 & 21 & 31 & 78 \\
\hline 98. & 24 & 19 & 37 & 80 \\
\hline 99. & & & & \\
\hline 100. & & & & \\
\hline 101. & 7 & 4 & 10 & 21 \\
\hline 102. & & & & \\
\hline 103. & & & & \\
\hline 104. & & & & \\
\hline 105. & 26 & 20 & 28 & 74 \\
\hline 106. & 15 & 7 & 21 & 43 \\
\hline 107. & & & & \\
\hline 108. & & & & \\
\hline 109. & & & & \\
\hline 110. & & & & \\
\hline 111. & 30 & 22 & 35 & 87 \\
\hline 112. & & & & \\
\hline 113. & & & & \\
\hline 114. & 17 & 3 & 15 & 35 \\
\hline 115. & & & & \\
\hline 116. & & & & \\
\hline 117. & & & & \\
\hline 118. & & & & \\
\hline 119. & & & & \\
\hline 120. & & & & \\
\hline 121. & & & & \\
\hline 122. & 20 & 19 & 24 & 63 \\
\hline 123. & & & & \\
\hline 124. & & & & \\
\hline 125. & 23 & 16 & 33 & 72 \\
\hline 126. & & & & \\
\hline 127. & & & & \\
\hline 128. & 10 & 4 & 17 & 31 \\
\hline 129. & & & & \\
\hline 130. & & & & \\
\hline 131. & 26 & 17 & 27 & 70 \\
\hline 132. & & & & \\
\hline 133. & & & & \\
\hline 134. & & & & \\
\hline 135. & 16 & 8 & 21 & 45 \\
\hline 136. & & & & \\
\hline 137. & & & & \\
\hline 138. & & & & \\
\hline
\end{tabular}




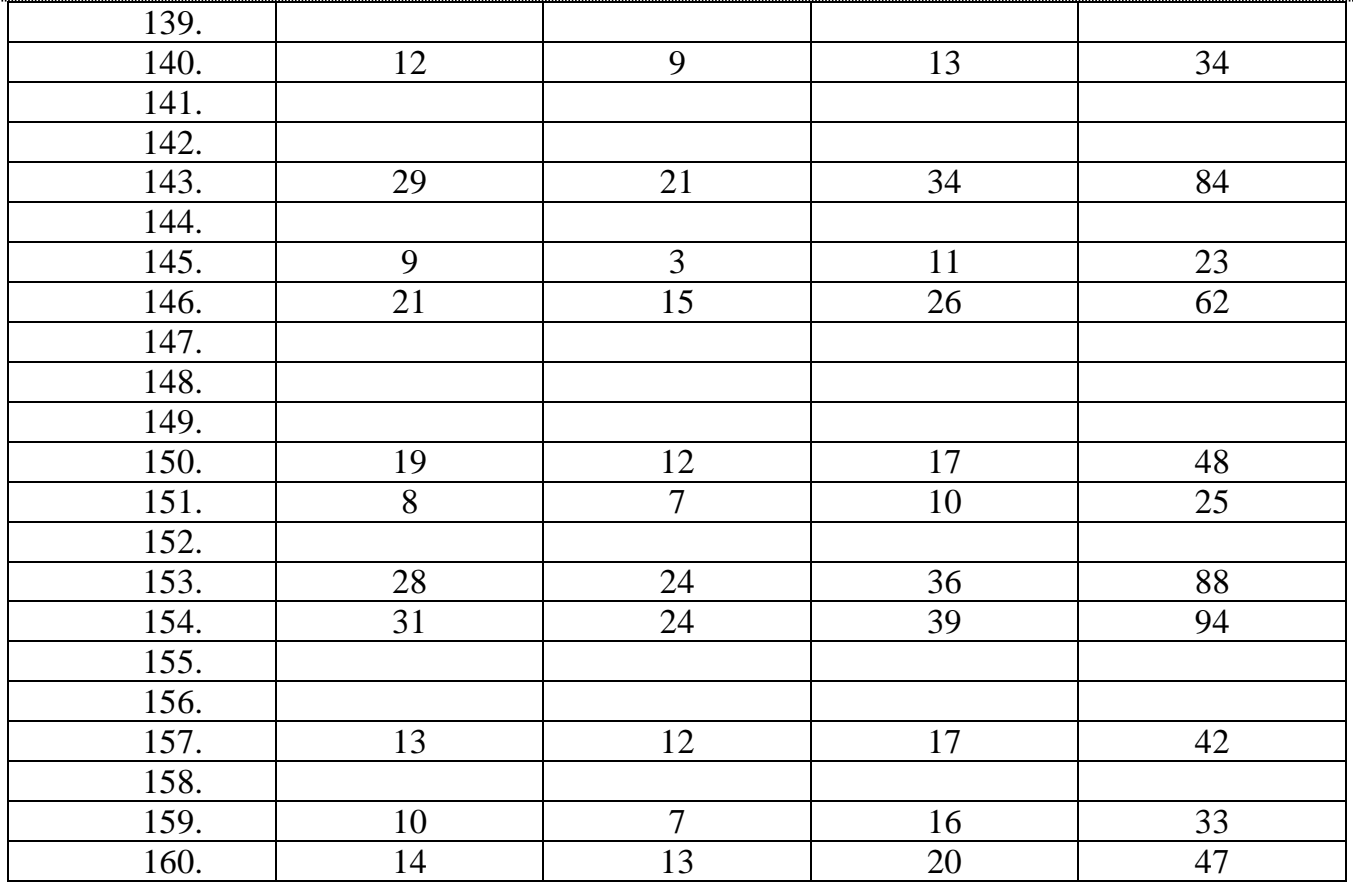

